\title{
NOTA
}

\section{Liberalismo, socialdemocracia y catolicismo social. Aproximación sociológica a las bases ideológicas de la construcción europea ${ }^{1-2}$}

\section{Eduardo Moyano Estrada ${ }^{3}$}

Palabras clave: Liberalismo, socialdemocracia, catolicismo, Unión Europea.

Key words: Liberalism, social democracy, Catholicism, European Union

Mots clés: Libéralisme, social-démocratie, catholicisme, Union Européenne

\section{Introducción}

El desarrollo de Europa occidental, con su culminación política e institucional en la Unión Europea (UE), puede verse como el resultado de diversos factores económicos, políticos y culturales, cuyo peso específico varía según donde se ponga el punto de mira a la hora de analizar ese largo y complejo proceso de construcción de un sistema político supranacional sin parangón en nuestro entorno.

\footnotetext{
${ }^{1}$ Artículo recibido en marzo de 2009. Versión definitiva de enero de 2010.

${ }^{2}$ Reproducción casi literal de la conferencia pronunciada el día 9 de diciembre de 2008 en el ciclo "Las raíces de la memoria de Europa. La segunda mitad del siglo XIX", organizado por el Aula de Religión y Humanismo de la Universidad de Córdoba. Agradezco a la dirección de la Revista de Fomento Social su gentileza invitándome a publicar el texto de la conferencia, a sabiendas de las limitaciones que eso entraña y de las inevitables simplificaciones que conlleva.

${ }^{3}$ Instituto de Estudios Sociales Avanzados (IESA) - Consejo Superior de Investigaciones Científicas, Córdoba.
} 
Hay quienes ponen el énfasis en los factores económicos, destacando la fuerza unificadora de una economía de mercado capaz de vertebrar el potencial disgregador de las divisiones ideológicas y políticas. Otros destacan la firme voluntad de la generación política de postguerra de crear una cultura de cooperación y diálogo entre los gobiernos de los distintos Estados, con el objetivo de evitar que se reprodujera en suelo europeo la trágica historia de luchas fraticidas de los dos últimos siglos - desde las guerras napoleónicas, hasta las franco-prusianas de final de siglo XIX, pasando por las dos grandes conflagraciones mundiales de la pasada centuria-. Finalmente, los hay que prefieren enfatizar el relevante papel desempeñado en todo ese proceso por los valores del cristianismo (tanto en su vertiente católica, como protestante), unos valores sin los cuales, señalan, no sería posible entender la Europa de hoy.

Este debate sobre las raíces de la construcción europea suele activarse en determinadas circunstancias. Hace unos años, durante la redacción de la frustrada Constitución europea (rechazada como sabemos en los referéndums francés y holandés celebrados en 2007), determinados grupos se esforzaron, sin éxito, en incluir en el preámbulo del proyecto constitucional una mención expresa al cristianismo por considerarlo base fundamental de la identidad europea. Más recientemente, con ocasión de los debates sobre las fronteras de la UE y, en concreto, sobre la entrada de países, como Turquía (de población mayoritariamente no cristiana), se esgrimen argumentos identitarios para establecer los límites del espacio europeo y para rechazar nuevas adhesiones. No obstante, también se utilizan argumentos meramente económicos o geopolíticos para precisamente lo contrario; arguyendo, por ejemplo, a favor de la adhesión de Turquía su pertenencia a la OCDE, su impecable tradición atlantista como miembro de la OTAN o su firme vocación europea formando parte del Consejo de Europa.

El propósito de este ensayo -que reproduce el contenido de una conferencia pronunciada hace algo más de un año- es contribuir al debate sobre las bases ideológicas de la construcción europea. Como punto de partida planteo la tesis según la cual Europa occidental, cuyo principal concreción político-institucional se encarna en la UE, es fruto de la síntesis virtuosa de tres grandes corrientes ideológicas: el liberalismo (tanto en su versión económica, como política), el socialismo (en su versión reformista y socialdemócrata) y el catolicismo social (tanto en su contribución a la doctrina socioeconómica del corporativismo, como al proyecto político democristiano). Gracias a esa síntesis, el modelo político, económico y social de la UE tiene una singularidad propia, que lo diferencia de otros modelos vigentes en el mundo de hoy. 
Indudablemente, los valores de la libertad individual encarnados en las distintas versiones del protestantismo forman parte de la cultura europea, y puede verse con nitidez su influencia en el desarrollo del liberalismo e incluso de la socialdemocracia en los países anglosajones. Sin embargo, es igualmente cierto que, al no estar vertebrado en una estructura eclesial de tipo jerárquico, sino en grupos y comunidades diversas, el protestantismo no construyó un cuerpo doctrinal propio para intervenir en los asuntos sociales y políticos, como sí lo hizo el catolicismo a través, primero, de las encíclicas papales, y luego, de la democracia cristiana. Ello hace que su presencia, indudable, en la construcción europea sea, sin embargo, más difusa, y más difícil de diferenciar, que las tres ideologías referenciales a las que dedicaremos el contenido de este ensayo.

Es evidente también que la reciente incorporación a la UE de los antiguos países del bloque soviético, supone la entrada de realidades culturales, económicas y políticas diferentes de las de los Estados fundacionales, desplazando el centro de gravedad hacia la Europa central y distorsionando en cierto modo algunos de los elementos claramente occidentales del proyecto tal como se definió a finales de los años 50 del pasado siglo. Si bien esto es verdad, también lo es que estos nuevos países se han integrado en la UE asumiendo el sistema de valores sociales, económicos y políticos (como la democracia parlamentaria, el reconocimiento de las libertades individuales, la economía de mercado y el desarrollo de la sociedad del bienestar), que constituyen las bases originarias del proyecto europeo y que siguen teniendo plena vigencia, tal como queda de manifiesto en el Tratado de Lisboa (cuya aplicación comienza el 1 de enero de 2010).

Es por esto que, a pesar de la gran diversidad interna de la UE-27, tiene sentido continuar hablando de algunas de las más importantes bases ideológicas de este proyecto, cuyas raíces históricas pueden situarse en el periodo que transcurre entre el último tercio del siglo XIX y primera mitad del s. XX, periodo donde se asientan los fundamentos modernos de la civilización europea occidental. Hablar de ello no significa, de ningún modo, dar argumentos para cerrar las puertas a la integración de nuevos países, ni dejar de reconocer la gran heterogeneidad social y cultural del espacio europeo en la actualidad. Desde mi punto de vista, los debates sobre las fronteras de la UE y los límites del proyecto europeo no deberían plantearse en términos identitarios, sino sobre la base de una cierta racionalidad instrumental en la que prime sobre todo el respeto a los valores democráticos y a la libertad individual, y en la que se promueva una economía de mercado adecuadamente regulada por los poderes públicos.

Sin otra pretensión que no sea, por tanto, la de contribuir a un mejor conocimiento

Revista de Fomento Social 65 (2010) 
de las bases ideológicas y culturales de la Europa que encarna la UE, desarrollamos nuestra argumentación señalando, en efecto, que el proyecto europeo es fruto de varios legados políticos, sociales y económicos, procedentes todos ellos de la combinación de tres corrientes ideológicas: el liberalismo, el reformismo socialdemócrata y el catolicismo social.

En lo que se refiere a la ideología liberal -en cuyo desarrollo tuvieron mucho que ver los efectos en los países anglosajones de la reforma protestante en sus distintas variantes-, cabe señalar como sus principales legados la economía de mercado, la propiedad privada, la libertad individual y la tolerancia religiosa.

Respecto a la herencia del reformismo socialista, cabe destacar, sobre todo, el relevante papel otorgado al Estado, y a los poderes públicos en general, en temas tales como la regulación de los fallos del mercado, la garantía de protección social a los ciudadanos, la reducción de las desigualdades económicas y la promoción de la igualdad de oportunidades en la población. Asimismo, y una vez abandonada la tesis marxista de la lucha de clases, destaca como legado socialdemócrata el protagonismo otorgado a los grupos intermedios de la sociedad civil (asociaciones patronales, organizaciones empresariales, asociaciones profesionales, sindicatos, ...) como vía para dirimir los conflictos mediante la negociación y la concertación social y para participar en la formulación y puesta en marcha de las políticas keynesianas en estrecha relación con los gobiernos.

En relación a la herencia del catolicismo social cabe distinguir tres legados: un legado ideológico/doctrinal -en cuyo centro sitúa a la persona como un fin en sí mismo que debe ser protegido, y del que deriva la asignación de un papel relevante a las familias como cemento social y como base de apoyo para la puesta en marcha de la sociedad del bienestar-; un legado político-encarnado en la democracia cristiana como partido confesional y en estrecha relación con la jerarquía católica-; y un legado de carácter socioeconómico -encarnado en la convicción de que la cooperación interclasista y los pactos corporativos son la mejor alternativa a la confrontación y la lucha de clases.

Planteada la tesis central de este ensayo, la desarrollaré en tres partes. En la primera, analizaré el contexto histórico de Europa en la segunda mitad del siglo XIX, y situaré de manera muy resumida las ideologías del liberalismo y del socialismo, frente a las cuales surgiría el corporativismo como alternativa de la Iglesia para que los católicos participaran activamente en la vida política y social. En la segunda parte, expondré los elementos claves del catolicismo social, con una especial atención a la doctrina corporativa, tal como fue concebida en las encíclicas papales 
Rerum Novarum y Quadragesimo Anno. Finalizaré con unas reflexiones sobre la vigencia de estos legados en el actual pensamiento social y en la praxis política de la UE en la nueva etapa que se abre tras las diversas ampliaciones y la entrada en vigor del ya citado Tratado de Lisboa. Es verdad que el espacio dedicado en esta conferencia a esas tres partes es desigual, prestándole más atención a la parte dedicada al catolicismo social, pero ello se justifica por el eje vertebrador de este ciclo de conferencias y por responder a las orientaciones de quien lo organiza, el Aula de Religión y Humanismo de la Universidad de Córdoba.

\section{El contexto histórico finisecular del $X \mid X$}

La Europa que conocemos no puede entenderse sin analizar el significado de la llustración y el impulso que representó al proceso de modernización social y política de la sociedad europea a lo largo del siglo XIX y parte del siglo XX. Es un largo periodo histórico de tránsito de la tradición a la modernidad, durante el cual viejos y nuevos valores, viejas y nuevas instituciones, viejos y nuevos modelos de sociedad, se enfrentan en el terreno de las ideas, de la práctica social y política, e incluso en el campo militar (con dos trágicas conflagraciones bélicas) hasta alumbrar, con la derrota del nazismo, una nueva era en la parte occidental del continente europeo.

De las cenizas de la guerra surgiría en la mayor parte de la Europa central y occidental una sociedad desposeída ya de los viejos residuos de la sociedad tradicional y encarnada en los principios de la democracia, la tolerancia religiosa, el individualismo liberal, la economía de mercado, la cooperación interclasista y el Estado social de derecho, que son los elementos fundamentales del modelo europeo que hoy conocemos y disfrutamos. Algunos países se incorporarán algo más tarde a este proceso -como fue el caso de España, Portugal y Grecia, una vez agotados o derrocados sus regímenes dictatoriales en los años 70-y otros (los países del Este europeo) lo han hecho recientemente en un complicado proceso de transición que aún perdura una vez desmanteladas las instituciones de los regímenes comunistas tras la caída del Muro de Berlín a finales de los años 80.

El periodo comprendido entre la segunda mitad del siglo XIX (una vez finalizadas las guerras napoleónicas) y la primera mitad del siglo XX, es un periodo atravesado por grandes convulsiones políticas y sociales, debido a la confluencia de diversos factores, entre los que me voy a permitir presentar de forma esquemática algunos de los que considero más relevantes para el hilo conductor de esta conferencia: 
a) El avance de la industrialización y el maquinismo, tras el paso de la primera revolución industrial (encarnada en la máquina de vapor y los talleres textiles) a la segunda (impulsada por la electricidad, la locomoción, la mecanización a motor, la industria química y metalúrgica, o el telégrafo).

b) La expansión de la economía capitalista y el libre mercado, con la consiguiente agudización de las desigualdades económicas y sociales, tanto dentro de los países industrializados, como a nivel mundial, con la emergencia de los grandes monopolios vinculados al imperialismo colonial.

c) El predominio de la razón y el conocimiento científico sobre los prejuicios y pseudosaberes vinculados muchas veces a la religión. A ello contribuiría la expansión de las ideas de filósofos y científicos cuyas ideas, expuestas en los siglos XVII y XVIII, cobrarían vigencia más tarde impulsando el pensamiento liberal y republicano. Entre ellos, cabe destacar filósofos como el judío sefardí Spinoza, los franceses Voltaire y Montesquieu o los alemanes Kant y Hegel, además de científicos como el francés Pascal, el británico Newton o, ya en el siglo XIX, el también británico Darwin.

d) El definitivo e inexorable declive de las instituciones del Antiguo Régimen (gremios, privilegios feudales,...) para hacer frente a los retos de una sociedad guiada cada vez más por el principio de la propiedad privada y la libertad individual.

e) La división de la sociedad en clases enfrentadas por el control de los medios de producción: sobre todo, la tierra, que, de haber sido objeto de uso y disfrute colectivo durante siglos, pasa a ser adquirida de forma privada por la nueva burguesía terrateniente, con la consiguiente exclusión del antiguo campesinado; ello dará lugar a las revueltas de los campesinos sin tierra, tan bien estudiadas en España por el jurista y sociólogo Constancio Bernaldo de Quirós en su obra "El espartaquismo agrario" (1919) o por el notario Juan Díaz de Moral en su célebre "Historia de las agitaciones campesinas en Andalucía" (1928).

f) La emergencia de nuevos movimientos sociales (en el ámbito del obrerismo) para darvozy salida a las reivindicaciones de los grupos menos favorecidos del proceso de modernización y desarrollo capitalista (tras el fracaso de las revoluciones de 1848, que situaron a estos grupos en los márgenes del sistema político).

g) El auge de los nacionalismos tras la decadencia de imperios como el otomano, el zarista o el austro-húngaro, que darán lugar a nuevas construcciones políticas en 
el centro y sur del continente europeo (como Hungría, Polonia, Bulgaria, Grecia, o los estados eslavos de la península balcánica, como Serbia o Croacia).

h) El nacimiento de nuevas ideologías (liberalismo, anarquismo, socialismo, corporativismo, ...) que, como cuerpo de doctrina, se ofrecerán para ayudar a la población a entender un mundo convulso e incierto, y para dar a los individuos identidad y un nuevo sentido de pertenencia.

A todo ello habría que añadir una coyuntura marcada por la llamada crisis económica finisecular, que agravaría las desigualdades económicas y las tensiones sociales haciendo más perentoria si cabe la necesidad de encontrar nuevas fórmulas políticas para poder gestionar una sociedad tan compleja, plural y heterogénea como era la sociedad europea de final del siglo XIX.

\section{El individualismo liberal y el colectivismo socialista, como ideologías referenciales}

En el contexto de la segunda mitad del siglo XIX, dos referencias ideológicas emergerán en el panorama europeo, dándole su impronta a los movimientos sociales y políticos de la época, a saber: el liberalismo y el socialismo. De forma esquemática expondré a continuación los elementos fundamentales que ayuden a entender el desarrollo de estas dos ideologías referenciales, ante las cuales el catolicismo construirá su propia doctrina social.

\section{I. Liberalismo}

Entre las propuestas que surgen para responder a los retos de la crisis finisecular, destacan las que se basaban en los principios del individualismo, la propiedad privada y la economía de mercado. Tales propuestas liberales se inspiran en diversas doctrinas ideológicas, cuyas raíces históricas hay que encontrarlas en antiguas tradiciones del pensamiento social y económico.

De un lado, estas propuestas arrancan de la tradición liberal británica, encarnada tanto en su versión política, como económica. Así, destaca la doctrina del liberalismo de la propiedad de John Locke; el liberalismo utilitarista de Hume; el liberalismo del comercio de Adam Smith; el utilitarismo "consecuencialista" y reformador de Jeremy Bentham, David Ricardo o James Mill; el liberalismo de la libertad de su 
hijo John Stuart Mill; el individualismo económico y librecambista de la Escuela de Manchester, o el liberalismo conservador de Edmund Burke (como reacción a la deriva violenta de la revolución francesa y su impacto en los círculos intelectuales británicos).

De otro lado, las propuestas liberales beben también de la tradición europea continental, con aportaciones tan señeras, aunque de efecto tardío, como la del ya mencionado judío sefardí Benito Spinoza (nacido en Amsterdam) (con su teoría racional y pragmática de la democracia) o la de los también citados franceses Voltaire (con su actitud de librepensador y de agudo crítico social de las instituciones absolutistas) y Montesquieu (con su apuesta por una moral laica y por la división de poderes en el ámbito políitico como garantía de equilibrio y estabilidad) y la de los llamados Enciclopedistas (por su empeño en editar la Enciclopedia, como auténtica expresión de los ideales ilustrados), que serían el fermento doctrinal de la revolución de 1789.

Más tarde, y como reacción a los hechos revolucionarios desarrollados en Francia, surgirían pensadores que revisarán las ideas liberales extremas y jacobinas abogando, de una parte, por la firme defensa de los derechos individuales (que conducirán a la democracia representativa), y de otra, por la necesidad de introducir límites al poder estatal, como el franco-suizo Benjamín Constant o el alemán Wilhelm von Humboldt. Otros pensadores destacarán la importancia de la sociedad civil en la solidez de las nuevas democracias, como el francés Alexis de Tocqueville, quien se convertiría en uno de los grandes fundadores de la sociología.

Toda esa panoplia de ideas y principios doctrinales servirán de base para la consolidación del liberalismo económico, el pluralismo político y la democracia de partidos, encarnados en los diversos sistemas de parlamentarismo. Obviamente, había variantes dentro del liberalismo, tantas como países, que darían lugar a distintos tipos de sistemas democráticos. Por ejemplo, puede distinguirse, de un lado, el sistema británico, orientado ya desde sus orígenes a fórmulas de concentración de la oferta política en un número reducido de partidos y que le conduciría al bipartidismo. De otro lado, el sistema centroeuropeo, donde pequeños partidos, de base territorial (caso de Bélgica) o religiosa (caso de Países Bajos), vertebran sus intereses a través de diversas estructuras de cooperación que han pervivido a lo largo del tiempo dándole singularidad a regímenes políticos destacados por los gobiernos de coalición y por la fortaleza de la sociedad civil. Junto a ellos cabe destacar también los casos de Francia y Alemania, donde el protagonismo del Estado ha sido su marca de origen, imponiéndose sobre un siempre debilitado sistema parlamentario. 


\subsection{Socialismo}

En contraposición al liberalismo, surgirían otras fórmulas, basadas inicialmente en las ideas primigenias de un socialismo de base más moral que política, y cuyas raíces podemos ya verlas en los grupos más radicales de los puritanos ingleses durante la revolución del siglo XVII (los levellers o niveladores, dirigidos por John Lilburne, y los diggers o cavadores, cuya figura más señera era Gerrard Winstansley).

Más tarde, tales ideas igualitaristas, desprendidas ya de toda justificación religiosa, aflorarán durante la revolución francesa en la llamada "conspiración de los iguales" (liderada por Babeuf, quien asumió el sobrenombre de Graco en homenaje a la familia patricia de ese mismo apellido, que destacó por su compromiso con los plebeyos durante la República de Roma en el siglo II a. de C. $)^{4}$. También pueden verse esas ideas igualitarias en los acontecimientos revolucionarios de la Comuna de París en marzo de 1871 tras la caída de la monarquía francesa por la derrota de Napoleón III en la guerra franco-prusiana.

Estas primeras ideas de socialismo primitivo negaban la propiedad privada como derecho natural y abogaban por formas diversas de propiedad colectiva o comunitaria, plasmándose en la práctica en experiencias concretas, tales como los falangsterios, las cooperativas o las sociedades de ayuda mutua de los socialistas utópicos (Saint-Simon y Fourier, en Francia, y Owen en Inglaterra). Tales ideas se irían concretando a lo largo del la segunda mitad del siglo XIX en el terreno político, dando lugar a la emergencia de movimientos sociales (llamados de forma genérica socialistas o colectivistas) que rechazaban la democracia parlamentaria por considerarla un instrumento al servicio de la burguesía y que apostaban por la agudización del conflicto de clases para, por vía revolucionaria o reformista, lograr la victoria del proletariado y alumbrar una sociedad sin clases y sin propiedad privada (sin explotadores ni explotados) y donde reinara el comunismo como ideal de igualdad.

Dentro del socialismo colectivista encontramos variantes, que van desde posiciones libertarias (como el anarquismo), hasta socialdemócratas, pasando por el socialismo más radical encarnado en el movimiento comunista.

${ }^{4}$ Babeuf publicó el "Manifiesto de los plebeyos" el 30 de noviembre de 1795 en el diario La Tribuna del Pueblo, considerado como un primer documento fundacional de la ideología socialista/comunista. Junto a Buonarroti organizó en París una conspiración revolucionaria contra el Directorio en la primavera de 1796, que fue reprimida, antes de que estallara, por el general Bonaparte la la sazón jefe del ejército del interior). Babeuf sería ejecutado un año más tarde. 
En relación con el anarquismo, se presentaba como un movimiento antiautoritario, que negaba cualquier tipo de autoridad (sea pública o privada) -de ahí que algunos autores, como Salvador Giner, en su Historia del Pensamiento Social (2008), hayan visto en las ideas anarquistas la expresión del individualismo más extremo-, que propugnaba la cooperación entre hombres libres e iguales a través de un sistema mutualista y federativo (consejos obreros) y que se guiaba sobre todo por principios morales (la bondad del ser humano, pervertido por el sistema de propiedad). Las ideas anarquistas pueden verse ya con nitidez en las obras del liberal radical inglés William Godwin (1756-1836) (con su confianza en la innata bondad del ser humano, sólo corrompido por la organización política de los gobiernos) y, sobre todo, en las del francés Pierre-Joseph Proudhon, primer autor que acuñó el término "anarquismo" (que significa "sin señor" o "sin gobernante") en su libro ¿Qué es la propiedad? publicado en 1840.

Con el tiempo, el anarquismo acabaría escindiéndose en dos vías. De un lado, la del anarquismo revolucionario, influido por el nihilismo ruso y encarnado en la figura señera de Mijail Bakunin (1814-1876). Esta vía radical era partidaria del uso de la violencia para la toma del poder, como paso previo al desmantelamiento del Estado, la abolición de la propiedad privada y el reparto de los medios de producción entre la población organizada en comunas y colectividades.

De otro, la vía del anarcosindicalismo, influido por las ideas utópicas del ya mencionado owenismo británico, y encarnado en figuras como la del príncipe ruso Kropotkin (1842-1921). Esta orientación más reformista preconizaba la vertebración de los trabajadores en sindicatos autónomos e independientes, con capacidad para convertirse en microcosmos donde la clase trabajadora pudiera encontrar no sólo una vía para la defensa de sus intereses, sino también respuesta a todas sus necesidades económicas y sociales mediante la creación de casas populares o cajas de ayuda mutua (para la vivienda, la educación, la protección ante el infortunio o la enfermedad,...) (En España, esta división del anarquismo se expresaría con nitidez en las distintas formas asociativas que adquirieron gran relevancia en los años 20 y 30 , como la FAl o la propia CNT, encarnadas en dirigentes como Buenaventura Durruti, Salvador Seguí, Juan García Oliver, Joan Peiró o Angel Pestaña, que han pasado a la historia del anarquismo español).

El llamado "socialismo científico" de Karl Marx y Frederic Engels (plasmado en su "Manifiesto comunista", escrito un año antes del estallido revolucionario de 1848) surgiría como reacción critica contra el mencionado socialismo utópico y moralista y contra otras formas de socialismo reformista-como el cartismo británico, que limitaba sus acciones a reivindicar la reducción de la jornada laboral y 
la extensión del sufragio universal a los trabajadores-, así como contra las ideas anarquistas con las que tuvo que enfrentarse en el seno de la I Internacional. El marxismo propugnaba un socialismo liberado de principios morales y basado en los principios hegelianos del material ismo histórico y dialéctico, donde el motor que impulsa el devenir histórico es la lucha de clases protagonizada en cada fase de la historia por distintos actores económicos y sociales (el campesinado, la burguesía, el proletariado,...). Para el socialismo marxista, la democracia parlamentaria era percibida no como un fin, sino como un medio, es decir, como una vía instrumental a utilizar por los partidos de los trabajadores para alcanzar el poder político y, una vez allí, aprovechar la fuerza coercitiva del Estado para, en un contexto de dictadura del proletariado, caminar por la senda del socialismo hasta alcanzar una sociedad sin clases. El modo instrumental con que trata el acceso al poder estatal y su utilización con fines revolucionarios, es la principal diferencia del socialismo marxista con el anarquismo, para quien el Estado no debe ser utilizado, sino desmantelado.

De ese tronco común del socialismo, se separarían diversas corrientes en función de las respuestas que fueron dando a las distintas realidades nacionales con las que tuvieron que enfrentarse. De un lado, se encuentra el marxismo leninista revolucionario, que, adaptando las teorías marxistas a la realidad de países atrasados como la Rusia zarista, potenciará el papel del partido comunista como vanguardia del proletariado y como guía para orientarlo por el camino de la revolución hacia el socialismo, destacando en ese proceso dirigentes señalados de la revolución soviética de Octubre de 1917, como Lenin o Trotski.

De otro lado, encontramos las distintas fórmulas del socialismo democrático, que, rechazando la vía revolucionaria de toma del poder político tras la experiencia soviética y su degeneración "stalinista", y aceptando la participación en las instituciones de la democracia parlamentaria, darían lugar a la socialdemocracia con sus variantes nacionales (socialdemocracia alemana, socialismo nórdico, socialismo de los países del sur de Europa,...).

A esa tendencia reformista del socialismo contribuirían pensadores tales como los alemanes Ferdinand Lassalle (1825-1864) (adalid del revisionismo socialista, fundador de la Unión General de Trabajadores y padre de la denominación "socialdemocracia"), August Babel (1840-1913) y Edouard Berstein (1850-1932); el austriaco Karl Kautsky (1854-1938) (autor de La cuestión agraria, programa agrario del SPD); el francés Jean Jaurés (1859-1914) (fundador del partido socialista SFIO), o como los ingleses integrados en la llamada "sociedad fabiana" creada en 1884 por un grupo de intelectuales británicos (como Herbert G. Wells, 
Bernard G. Shaw, Beatrice Potter, Sydney Webb, ... $)^{5}$, cuyas ideas ejercerían posteriormente gran influencia en el laborismo inglés.

En el caso español, la historia del PSOE, creado en 1879 por Pablo Iglesias, es el vivo reflejo de la confrontación entre dos visiones del socialismo: una, más radical y revolucionaria (encarnada en dirigentes como Araquistáin o Largo Caballero) y otra, más moderada y socialdemócrata (donde destacan dirigentes como Fernando de los Ríos, Indalecio Prieto o Julián Besteiro) que es en la que se inspira el socialismo español surgido durante la transición democrática de la mano de Felipe González.

\section{La respuesta del catolicismo a la lucha de clases}

En ese contexto de final del siglo XIX, y en el marco de una profunda crisis económica (la mencionada "crisis finisecular", provocada por la llegada de cereales a precios bajos procedentes sobre todo de América en lo que sería un anticipo de la globalización), surgirían las propuestas de movilización social preconizadas por la Iglesia católica. Tales propuestas se harían a través de la encíclica Rerum Novarum (Sobre las nuevas cosas) escrita en 1891 por el Papa León XIII (de nombre de pila Gioacchino Pecci, antes cardenal de Peruggia), y a la que se le califica de primera encíclica social.

En esa encíclica (subtitulada "Sobre la situación de los obreros") el Papa hace un diagnóstico de la sociedad de fin de siglo. De un lado, manifiesta su preocupación por las desigualdades sociales generadas por la "codicia de unos pocos" y por la situación de los pequeños campesinos y de los obreros de las industrias emergentes. De otro lado, descalifica la opción socialista como vía para solucionar los problemas de los trabajadores, por considerarla una ideología que promueve el odio y el ateísmo.

En su encíclica, León XIII deplora la opresión y esclavitud de los numerosísimos pobres por parte de "un puñado de gente muy rica", preconiza salarios justos y plantea el derecho de los trabajadores católicos a organizarse en sindicatos. Sin

${ }^{5}$ El nombre de sociedad fabiana lo toman en homenaje al general romano Fabio Cunctator, famoso por su paciencia y sangre fría al rehusar la confrontación directa en su enfrentamiento con el cartaginés Anibal. Al tomar como referencia la figura de este general romano, los fabianos apostaban por la lucha gradual y no violenta contra el capitalismo. 
embargo, rechazaba vigorosamente el socialismo y mostraba poco entusiasmo por los sistemas democráticos (pensemos en la animadversión de la Iglesia contra el nuevo régimen político italiano instaurado por Garibaldi y que había disuelto los Estados Pontificios). Las clases sociales y la desigualdad, afirmaba León XIII, constituyen rasgos inalterables y consustanciales de la condición humana, por lo que el socialismo y su proyecto de construir una sociedad sin clases, es una ideología ilusoria, poco realista. Además de por ilusorio, el socialismo es condenado en la Encíclica por sembrar el odio y el ateísmo entre los seres humanos, lo que no le impide a León XIII hacer una crítica feroz de la rapacidad, el egoísmo y la inmoralidad de los empresarios capitalistas, si bien ensalzando el valor de la propiedad y del mercado como elementos de bienestar.

Con ello, León XIII intentaba superar el pensamiento católico reaccionario de los que no aceptaban los cambios económicos y sociales de la época y preconizaban un retorno al Antiguo Régimen (como el conde saboyano Joseph de Maistre, con su divisa "trono y altar", y todos los que como De Bonald proponían la restauración monárquica tras los hechos revolucionarios). La Encíclica buscaba conciliar dentro de la comunidad de católicos las ideas del pensamiento reaccionario y las del liberalismo conservador, encarnado éste en figuras como los pensadores españoles Donoso Cortés (1809-1853) o Jaime Balmes (1810-1849), que comprendían la inviabilidad del regreso al absolutismo del antiguo régimen y abogaban por reformas graduales que se anticiparan a la marea revolucionaria.

Era, en definitiva, un intento por construir sobre bases morales (que no religiosas) una doctrina que, respetando el valor del nuevo orden económico, sirviera para evitar sus desviaciones y efectos perversos. Con ella, León XIII aspiraba a impulsar la idea del católico integrado en comunidades y grupos primarios (la familia y la iglesia), pero también en asociaciones alejadas de los antiguos gremios y adaptados a la sociedad moderna de fin de siglo.

Como alternativa, la Encíclica ofrecía una ideología de integración interclasista en la que, negando por utópico el igualitarismo propugnado por los movimientos marxistas, y atacando el egoísmo del individualismo capitalista, tuviera cabida de forma armoniosa los intereses de los empresarios y de los asalariados sobre la base del consenso económico y social. En su encíclica, León XIII se inspiraba, sin duda, en el organicismo spenceriano tan en boga por aquellos años, pero también en las ideas de los círculos católicos seglares, como la "Unión católica de estudios sociales y económicos", conocida también como "Unión de Friburgo" -dirigida por Lovis La Tour du Pin (1834-1924) y Albert de Mun (1841-1914)-, que preconizaba ya entonces la vertebración de la sociedad en corporaciones interclasistas. 
La encíclica concibe la sociedad como un cuerpo, en el que todas sus partes son necesarias para el funcionamiento del todo, y en el que la religión católica debe jugar el papel del cemento que posibilite las relaciones sociales entre grupos e individuos con intereses inevitablemente distintos, pero no irreconciliables. A ello le unirá la exaltación del papel de la familia, como reducto de libertad donde no debe entrar ningún poder político ni civil. Esta idea de la sociedad como un cuerpo guiado por los principios morales de la religión y basado en la estructura de la familia, es lo que daría pie a que se denominara corporativismo a la doctrina surgida de esta primera encíclica social de la Iglesia.

La encíclica hace también un llamamiento a que los católicos participen activamente en la vida social, y sobre esta base surgirían las primeras organizaciones católicas en el ámbito de los sindicatos y asociaciones (círculos obreros, organizaciones juveniles de estudiantes, asociaciones campesinas, cooperativas,...). En España, su mejor expresión sería la Asociación Católica de Propagandistas, creada en 1909 por el sacerdote jesuita Ángel Ayala (1867-1960) para agrupar a católicos seglares, entre los que destacaría un jovencísimo abogado, Angel Herrera Oria (1886-1968), que sería su primer presidente y que luego se haría sacerdote hasta alcanzar la púrpura cardenalicia. En esta misma línea, aunque con otra visión pastoral (no corporativa), puede situarse el movimiento de católicos seglares promovido por el sacerdote José $M^{a}$ Escrivá de Balaguer (1902-1975) y que daría lugar al Opus Dei en 1928.

Aunque la Rerum novarum era un encíclica dirigida sobre todo a analizar el nuevo orden capitalista en el mundo industrial y urbano, el llamamiento a los católicos encuentra eco sobre todo en el mundo rural y agrario, que era donde vivía la inmensa mayoría de la población de final del siglo XIX y primera década del siglo XX. Así, nacieron los primeros sindicatos agrarios católicos y las primeras cooperativas en países europeos como Francia, Italia o España, impulsando, con el apoyo firme y decidido del clero, formas alternativas al sindicalismo de base marxista o anarquista que ya estaba muy extendido en el medio rural. Lo novedoso del corporativismo católico, y lo que le dará su impronta, era su denodada defensa del pequeño campesinado, despreciado por la ideología marxista por atrasado e individualista, y por ser un residuo del Antiguo Régimen (recordemos la expresión de Marx al calificarle como "un saco de patatas" en su obra El 18 Brumario de Luis Bonaparte publicada en 1852).

La permanencia del modelo de explotaciones agrarias de tipo familiar, o el amplio desarrollo del cooperativismo en la agricultura europea, no pueden explicarse sin hacer mención al papel desempeñado por los movimientos católicos mediante la 
propagación de la ideología corporativista. En su afán por evitar que el individualismo liberal -encarnado en el principio de la hegemonía del mercado y la lógica del beneficio capitalista- condenara al pequeño campesinado a la proletarización y a la exclusión social y económica, y en su empeño por impedir que los trabajadores fueran atraídos a las filas del movimiento socialista, la Encíclica ofrecía una tercera vía, el de la unión mixta e interclasista en el seno de estructuras corporativas donde trabajadores y empresarios, grandes agricultores y pequeños campesinos, pudieran compartir intereses comunes. En esas corporaciones, los movimientos católicos, impulsados por la jerarquía de la Iglesia, proponían la cooperación y la ayuda mutua de todos los ciudadanos del mundo rural (donde estarían encarnadas las virtudes del ahorro, el trabajo, la entrega y la solidaridad) frente al egoísmo de los particularismos individuales preconizado por el liberalismo, y propugnaban la integración en torno al interés general frente a la división y la lucha de clases preconizada por el socialismo.

En ese contexto cabe citar algunas de las asociaciones católicas que jugaron un importante papel en la vertebración del pequeño campesinado, como la española Confederación Católica Agraria (estudiada de forma brillante por Juan José Castillo en su libro Campesinos muy pobres, editado en 1979), la italiana Coldiretti o la francesa JAC (Juventud Agraria Católica), que sería, gracias a las aportaciones de pensadores católicos como Emmanuel Mounier (1905-1950), el embrión de lo que más tarde se convertiría en el poderoso sindicato de jóvenes agricultores (la CNJA). El movimiento de las Escuelas Familiares Agrarias -iniciado en Francia con las Maisons Familiales Rurales en 1937 por Marc Sangnier a través del llamado grupo de Sillon, y luego continuado en otros países como España gracias al impulso del Opus Dei- puede verse como otra expresión del compromiso del catolicismo con el mundo rural.

Cabe afirmar, en definitiva, que, sin la ideología corporativista del catolicismo social, los intereses del pequeño campesinado se habrían visto abandonados o diluidos en el creciente proceso de proletarización propugnado desde las filas del marxismo en sus distintas variantes.

La encíclica Quadragesimo anno-escrita en 1931 por el papa Pío XI (1857-1939), con motivo del cuarenta aniversario de la Rerum Novarum- viene a dar contenido programático al movimiento católico y a la acción social de la lglesia en un contexto diferente al que existía cuarenta años atrás ${ }^{6}$. Su pontificado estuvo marcado

${ }^{6}$ Pío XI fue elegido Papa en 1922, sucediendo a Benedicto XV, y murió en 1939. Su nombre de pila era Achille Ratti. Fue nuncio papal en Polonia, y antes de su elección como Papa era arzobispo de Milán. 
por la crisis de la Gran Depresión y sus efectos sociales y económicos en forma de pobreza, desempleo y conflictividad, lo que explica la preocupación de Pío XI por los problemas económicos y sociales y por su interés en dotar a los católicos de una buena guía doctrinal para iluminarlos en los complejos avatares de la época. Asimismo, fue un papado marcado por la emergencia de los regímenes fascistas en pleno periodo de entreguerras, con los que mantendría una relación bastante ambigua ${ }^{7}$.

En lo que se refiere al contenido de su Encíclica, aunque hay una continuidad evidente con la Regnum Novarum, las diferencias son también claras. Mientras que en la de León XIII, el tema central era lo que podríamos llamar la cuestión obrera, expresando la preocupación de la Iglesia por el estado de creciente pauperización de los trabajadores en las primeras fases del capitalismo individualista y codicioso, y por los efectos perniciosos de la lucha de clases, la Quadragesimo Anno se publica en un escenario diferente. El capitalismo se había extendido en forma de grandes monopolios, afectando al conjunto de la sociedad, y el socialismo se había diferenciado internamente con la ruptura producida por la III Internacional (promovida por Stalin) entre revolucionarios (los partidos comunistas) y reformistas (los partidos socialdemócratas). Ya no se dirige la Encíclica a velar por la armoniosa relación entre patronos y obreros dentro de las empresas (cuestión obrera), sino que trata de analizar la complejidad de la vida económica y social ampliando el horizonte de su mensaje doctrinal.

Es la cuestión social el eje central de esta segunda Encíclica, ofreciendo una visión orgánica del orden socioeconómico imperante en los países europeos, y dando mensajes concretos de cómo orientar las políticas y los contenidos programáticos de las asociaciones católicas. Pío XI da gran importancia en su encíclica a la restauración del principio rector de la economía, que basa en la unidad del cuerpo social, una unidad que no puede basarse en la lucha de clases, al igual que tampoco puede basarse el orden económico en la libre concurrencia de las fuerzas del mercado. El libre mercado es útil y beneficioso, pero, en opinión de Pío XI, no puede gobernar el mundo convirtiéndose en una especie de dictadura económica.

7 Pío XI firmó el importante Tratado de Letrán (1929) con el gobierno de Mussolini, por el cual se reconocía el Estado Vaticano. A cambio, expresó inicialmente un claro apoyo al fascismo italiano, hasta el punto de que, a cambio, aceptó la disolución del Partido Popular (católico) de Luigi Sturzo (precursor de lo que sería más tarde la democracia cristiana). Más tarde, al final de su papado, se mostraría muy crítico con el régimen fascista. Lo mismo ocurrió con su actitud ante el régimen nazi, que, de un apoyo inicial (firmando incluso un concordato en 1933 con el gobierno de Hitler), pasó a una clara posición crítica, publicando en 1937 la encíclica Mit brennender Sorge (Con ardiente preocupación), en la que condenaba el nazismo. 
Como alternativa, propone un mundo regido por la caridad y la justicia social, y regulado por los poderes públicos, que, en opinión del Papa, han de evitar tanto el individualismo exacerbado, como el colectivismo.

La Quadragesimo Anno suaviza el tono de anatema contra el socialismo que empleaba la Rerum Novarum y abre vías de colaboración con los partidos políticos y asociaciones reformistas de izquierda. En este sentido es destacable el hecho de que amplía el horizonte asociativo de los católicos, propugnando que si no pueden integrarse en asociaciones puramente católicas lo hagan en otras asociaciones, aunque manteniendo la defensa de los principios cristianos dentro de ellas. Ello significaría un enorme potencial de cambio en Europa al propiciar el diálogo político entre católicos y no católicos.

\section{I. La herencia del catolicismo social}

A la hora de analizar cuál ha sido el legado de la doctrina social de la Iglesia, y proyectarla desde una perspectiva más actual, cabe distinguir tres niveles.

En primer lugar, el nivel político, con efectos de diversa índole, no exentos de contradicciones. De un lado, haber dado soporte doctrinal e ideológico a los regímenes corporativos autoritarios surgidos entre las décadas $20-40$ del siglo XX, como el fascismo italiano, el salazarismo portugués o el franquismo español -y más tarde el Estado Novo de Getulio Vargas en Brasil-, que organizan el Estado a través de corporaciones interclasistas de adscripción obligatoria (donde pueden verse rastros del corporativismo católico). Este efecto es, en cierto modo, consecuencia directa de la desconfianza ya mostrada en la Rerum Novarum hacia el pluralismo y los sistemas democráticos, desconfianza que con la Quadragésimo Anno se atemperará, y que definitivamente desaparecerá cuando la democracia cristiana, tras la caída del fascismo italiano y su derrota en la II Guerra Mundial, abrace el ideal democrático y se convierta en uno de los pilares de la construcción europea. De otro lado, cabe señalar cómo las ideas corporativistas del catolicismo social, adecuadamente renovadas y adaptadas a contextos democráticos, sirvieron de base a las políticas de pactos sociales que se desarrollaron en los países europeos de postguerra (sobre todo, en Italia y Alemania, gracias al buen entendimiento entre políticos democristianos y socialdemócratas) y que dieron lugar a que desde la ciencia política y la sociología se acuñara el término "neo-corporativismo" 8 .

${ }^{8}$ A comienzos de los años 70, renace el corporativismo de la mano de la teoría política, gracias al politólogo norteamericano, Philippe Schmitter, quien publica en 1973 un artículo denominado "Still 
En segundo lugar, el legado del catolicismo social puede verse también en el nivel de la vertebración de intereses en el ámbito de la sociedad civil, donde proliferarán fórmulas corporativas de adscripción obligatoria para la defensa y regulación de determinadas profesiones, dando lugar, por ejemplo, a los colegios profesionales o las cámaras agrarias y de comercio. Asimismo, inspiradas en la doctrina católica, se desarrollará en muchos países europeos el cooperativismo católico en distintos campos, así como las cajas de ayuda mutua, las primeras cajas de ahorro y gran número de entidades educativas y asistenciales. De ese caldo de cultivo surgirían, por ejemplo, en España instituciones como la mencionada Asociación Católica de Propagandistas, que han tenido una gran relevancia en la presencia social del catolicismo seglar: la Editorial Católica, la Confederación Nacional de Estudiantes Católicos, la primera Escuela de Periodismo de España, vinculada al diario El Debate, el Instituto Social Obrero o el Centro de Estudios Universitarios (CEU), del que nacerían a finales del siglo XX varias universidades. A ello habría que añadir toda la red de asociaciones juveniles y obreras del tipo de las JEC, JOC, HOAC, que jugaron un importante papel en la transición política española durante los años 70, impulsados por una jerarquía eclesiástica comprometida con el cambio hacia la democracia y con el compromiso social de los católicos.

En tercer lugar, el legado católico se observa también en el ámbito del asociacionismo agrario, donde el catolicismo social dará pie a la consolidación de las organizaciones orientadas a la defensa de la agricultura familiar, impregnando también por contagio al movimiento campesino de izquierda (tanto de raíz comunista como socialista, una vez revisada su posición respecto al campesinado).

Por ejemplo, a las organizaciones agrarias de base católica, como las ya mencionadas Coldiretti o CNJA, se les unirán en la defensa de los pequeños agricultores

of the century of corporatism?", donde, analizando la dinámica de pactos sociales entre gobiernos, patronal y sindicatos que venía caracterizando a la política europea de postguerra bajo gobiernos socialdemócratas o democristianos, se pregunta si acaso no se estaba asistiendo a una refundación del corporativismo. Schmitter se cuida de no identificar este escenario proclive a la concertación, con el viejo corporativismo asociado a los regimenes autoritarios no democráticos, y por eso le llama "neocorporativismo", dando a entender que con ese término pretende resaltar el predominio de los intereses generales sobre los intereses particulares, y la superación de la lucha de clases en las sociedades industriales avanzadas. En torno al neocorporativismo se produce una especie de síntesis entre el liberalismo (al respetarse los grandes principios de la economía de mercado), la socialdemocracia (al postular el papel regulador del Estado en la economía) y el catolicismo social (al apostarse por la colaboración entre los grupos de intereses y la cooperación interclasista). La concreción de esta idea puede verse hoy en muchos ámbitos de la vida social, económica y política, constituyendo uno de los ejes principales en el funcionamiento de los sistemas democráticos y de bienestar, que son el rasgo distintivo de la Unión Europea. 
organizaciones de la gauche paysanne como la Confédération Paysanne francesa, la Allianza Contadina italiana (más tarde refundada como Confcoltivattori), la portuguesa CNA o las españolas COAG y UPA. Bien es verdad que el interés de la izquierda por los temas relacionados con la pequeña agricultura familiar se produce bien entrada la segunda mitad del siglo XX, en el marco del proceso de construcción de la Unión Europea y de formulación de la PAC (política agraria común), una vez que economistas de formación marxista-como el francés Claude Servolin, en su trabajo "L'absortion de l'agriculture dans le mode de production capitaliste" (1972)- analicen la funcionalidad y eficiencia de las explotaciones familiares agrarias y comprueben el fracaso de las grandes granjas colectivas, contradiciendo así lo que habían sido las previsiones del ya mencionado Karl Kautsky en su obra clásica La cuestión agraria escrita para el congreso del SPD alemán.

\section{Conclusiones}

Las democracias europeas son hoy el fruto de diversos legados. Un primer legado corresponde a los principios del individualismo liberal, que-gracias a la influencia de los valores preconizados por el protestantismo- han contribuido a la consolidación de sistemas abiertos en materia de pensamiento, tolerancia religiosa y práctica política, al desarrollo de la economía de libre mercado y al protagonismo de una sociedad civil encarnada en la defensa de los derechos individuales de los ciudadanos.

Un segundo legado procede, sin duda, del socialismo democrático, que tras la experiencia comunista, revisó sus principios ideológicos para adaptarlos a la realidad de una sociedad como la europea de los años 50, basada en la economía de mercado y el Estado Social de Derecho. Desde unas políticas keynesianas de intervencionismo estatal, la socialdemocracia -como expresión política más acabada del reformismo socialista, sobre todo a raíz de la renuncia del SPD alemán al marxismo en su congreso de Bad Godesberg en 1959- contribuiría al desarrollo de los Estados del Bienestar, teniendo una gran repercusión en los partidos socialistas del sur de Europa, como el español, portugués o griego.

Finalmente, habría que destacar el legado del catolicismo social que, al igual que hizo el socialismo, tuvo que revisar sus principios doctrinales para aceptar el pluralismo y la diversidad política e ideológica y adaptarse a la situación de libertad y tolerancia religiosa que caracterizan a las sociedades abiertas -teniendo 
en ello un papel fundamental el Concilio Vaticano II-. El legado del catolicismo se manifiesta, sobre todo, en la sensibilidad que manifiestan los católicos y sus organizaciones políticas (democristianas) y sociales en temas relacionados con la pobreza, la exclusión y la marginalidad en muchos ámbitos: sea la agricultura y el mundo rural (defendiendo la pequeña agricultura familiar); sea el mundo de los "sin techo", de los enfermos y desamparados, o de la inmigración (haciendo posible el modelo asistencial de muchos países europeos, que descansa en las redes familiares y religiosas); sea el ámbito de las relaciones Norte-Sur y en lo relativo a las desigualdades entre países ricos y pobres (con la proliferación de organizaciones no gubernamentales de raíz cristiana).

En definitiva, como señalé al comienzo de mi conferencia, la actual sociedad europea no puede comprenderse sin hacer referencia a las herencias políticas y culturales de estas tres ideologías -con la presencia ampliamente extendida de los valores de la libertad individual preconizados por el protestantismo-, habiendo estado muy presentes en el proceso de construcción de la Unión Europea. Recordemos que los promotores de ese proceso procedían de las filas de esas tres corrientes políticas: los franceses Jean Monnet (1888-1979) (liberal) y Robert Schuman (1886-1963) (democristiano), el alemán Konrad Adenaver (1876-1967) (democristiano), los italianos Alcide de Gaspieri (1881-1954) (democristiano) y Altiero Spinelli (1907-1986) (comunista), el belga Paul Henry Spaak (1899-1972) (socialista) o el holandés Sicco Mansholt (1908-1995) (socialista).

Esas ideologías supieron renovarse y adaptarse a la realidad de una sociedad europea en transformación -como era la Europa occidental de postguerra- renunciando a sus principios maximalistas y estableciendo lazos de cooperación y encuentro entre ellas. De esa voluntad de cooperación somos todos herederos, una herencia que debemos conservar en pro de la Europa del siglo XXI, donde se integran países procedentes de ámbitos culturales e ideológicos distintos de los que fueron la base inicial del proceso de construcción europea. El reto actual de una UE-27 y con la perspectiva de nuevas ampliaciones, pasa precisamente por renovar el pacto fundacional, manteniendo los valores fundamentales de la libertad individual, la tolerancia religiosa, la economía de mercado, el papel regulador del Estado y un sistema de bienestar que evite la exclusión y contribuya a reducir las desigualdades sociales y económicas. 